\title{
Development, validation and clinical use of the Eating Behaviors Assessment for Obesity (EBA-0)
}

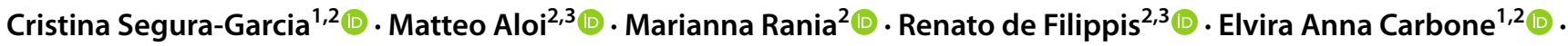 \\ Silvia Taverna ${ }^{1} \cdot$ Maria Cristina Papaianni ${ }^{4} \cdot$ Marco Tullio Liuzza' $^{1}$ (i) Pasquale De Fazio ${ }^{3}$ (I)
}

Received: 2 November 2021 / Accepted: 8 January 2022 / Published online: 29 January 2022

(c) The Author(s), under exclusive licence to Springer Nature Switzerland AG 2022

\begin{abstract}
Introduction Obesity is a major health problem with an increasing risk of mortality, associated with comorbidities and high rates of dropout. Research demonstrated that pathological eating behaviors could help to phenotype obese patients thus tailoring clinical interventions. Therefore, our aim was to develop (study 1), validate (study 2), and test in a clinical setting (study 3) the Eating Behaviors Assessment for Obesity (EBA-O).

Method Study 1 included the exploratory factor analysis (EFA) and McDonald's $\omega$ in a general population sample $(N=471)$. Study 2 foresaw the confirmatory factor analysis (CFA) and convergent validity in 169 participants with obesity. Study 3 tested the capability of the EBA-O to characterize eating behaviors in a clinical sample of 74 patients with obesity.

Results Study 1. EFA identified five factors (i.e., food addiction, night eating, binge eating, sweet eating, and prandial hyperphagia), explaining $68.3 \%$ of the variance. The final EBA-O consisted of 18 items. McDonald's $\omega$ ranged between 0.80 (hyperphagia) and 0.92 (binge eating), indicating very good reliability. Study 2. A second-order five-factor model, through CFA, showed adequate fit: relative chi-square $\left(\chi^{2} / d f\right)=1.95, \mathrm{CFI}=0.93, \mathrm{TLI}=0.92, \mathrm{RMSEA}=0.075$, and SRMR $=0.06$, thus suggesting the appropriateness of the EBA-O model. Significant correlations with psychopathological questionnaires demonstrated the convergent validity. Study 3. Significant associations between EBA-O factors and emotional-related eating behaviors emerged.
\end{abstract}

Conclusion The EBA-O demonstrated to be a reliable and easy-to-use clinical tool to identify pathological eating behaviors in obesity, particularly useful for non-experts in eating disorders.

Level of evidence Level V, descriptive research.

Keywords Obesity $\cdot$ Test $\cdot$ Validation $\cdot$ Eating behavior $\cdot$ Psychometric properties

Cristina Segura-Garcia, Matteo Aloi and Marianna Rania are joint first authors.

Marianna Rania

marianna.rania@hotmail.it

1 Department of Medical and Surgical Sciences, University Magna Graecia of Catanzaro, Catanzaro, Italy

2 Center for Clinical Research and Treatment of Eating Disorders, University Hospital Mater Domini, Catanzaro, Italy

3 Department of Health Sciences, University Magna Graecia of Catanzaro, Catanzaro, Italy

4 Italian Ministry of Education, Crotone, Italy

\section{Introduction}

Obesity is a multifactorial systemic metabolic disease that cannot be confined to an aesthetic problem; moreover, it has become a serious worldwide public health problem, as well as a severe individual health problem in recent decades [1]. Obesity is clinically relevant as its medical consequences are associated with high morbidity, poor quality of life, and high mortality rates. Indeed, according to the World Health Organization (WHO), at least 2.8 million people die due to overweight or obesity every year [2]. The treatment is manifold and characterized by high dropout rates and poor long-term efficacy. Current therapeutic choices provide a multistep progression that includes dietary and behavioral changes, physical activity, drug treatment, up to bariatric surgery in selected cases [3-6]. However, although bariatric 
surgery seems to be the most effective treatment for obesity, some individuals do not respond adequately, especially in the long-term evaluation [7]. Furthermore, specific subgroups of patients with obesity may report persistent or de novo pathological eating behaviors even after bariatric surgery [8]. On the other hand, obesity is bi-directionally associated with both physical and psychiatric diseases [9]. Psychiatric comorbid disorders (e.g., binge eating disorder, affective disorders, and anxiety disorders) may overlap silently, thus impairing treatment response and prognosis. Therefore, an adequate characterization of each patient with obesity is crucial to choose the most effective and personalized treatment, and reduce dropouts.

Several altered eating behaviors have been described so far among patients with obesity other binge eating [10] (i.e. eating a large amount of food in short time with the sense of loss of control over eating [11]). Grazing is considered the repetitive eating (more than twice) of small/modest amounts of food in an unplanned manner with or without compulsive features [12]. Recurring episodes of eating after awakening from sleep and the excessive food consumption after the evening meal are, respectively, coined as night eating and post-dinner eating [11]. Food addiction is the uncontrolled eating of some high-fat and high-sugar palatable foods [13], while having sweet tooth and/or eating sweet meals and beverages triggered by emotional factors is so called as sweet eating. Emotional eating is a large and ambiguous concept that involves eating in response to emotionally charged or stressful situations with loss of control over eating highcaloric meals without being hungry. Social eating is meant as an overeating which takes place preferentially in situations of conviviality whilst hyperphagia refers to the excessive energy intake or overeating during the main meals without losing control (i.e., larger portions or bis). Orthorexia regards the obsession with healthy food eating to promote optimum health [14]. Finally, behaviors aimed at controlling weight or body shape among patients with obesity are typically: restriction (i.e. the reduction of food intake) and fasting (i.e. restriction of food or drink intake for at least $8 \mathrm{~h}$ a day while awake).

Promising exploratory research findings have shown that patients with obesity may be phenotyped according to their pathological eating behaviors [15]. In this regard, two opposite clusters emerged: the first included those who mainly exhibited prandial hyperphagia and social eating; the second cluster comprised patients with more emotionally related eating behaviors (i.e., binge eating, emotional eating, grazing, night eating, post-dinner eating, sweet eating and craving for carbohydrates) [15]. Still, dysfunctional personality traits, neurocognitive impairment, affective disorders, and increased frequencies of the short $(\mathrm{S})$ allele and the $\mathrm{S} / \mathrm{S}$ genotype of serotonin transporter were more frequent in the second cluster. Consequently, authors suggested that eating behaviors might avail to differentiate patients with obesity and concurrent psychiatric comorbidities.

Several valuable tools evaluating separately the pathological eating behaviors already exist. The most frequently used to assess eating behaviors in the population of obese patients are: Binge Eating Scale [16], Night Eating Questionnaire [17], Yale Food Addiction Scale 2.0 [18], Grazing Questionnaire [19], Dutch Sweet Eating Questionnaire [20]. Unfortunately, the administration and correction of all these tests would require a lot of time and specialized training; this makes their use difficult where there is no specialized figure in the team and the time available for the administration of tests is limited. Thus, a specific and reliable tool evaluating simultaneously all these pathological behaviors could be easier-to-use and valuable in the clinical practice.

Based on the above, our goal was to develop (study 1), validate (study 2) and test in a clinical setting (study 3 ) a reliable and easy-to-use instrument to facilitate the identification of pathological eating behaviors of patients with obesity.

\section{Study 1: factor structure and internal consistency of the EBA-O}

The purpose of study 1 was to examine the factorial structure and internal consistency of the Eating Behaviors Assessment for Obesity (EBA-O) in a large sample of participants.

\section{Participants}

A convenience sample from the general population was recruited between February and May 2021 through an online survey posted on Facebook. Participants were informed about the purpose of the study, the procedures, the voluntary nature of participation, the anonymity and the management and retention of data. Finally, they consented to participate by clicking on the consent box. Sociodemographic data included age, sex, education, occupation, height, weight, and life style. Answers from participants aged below 18 or above 65 years old were discarded. The investigation was approved by the Ethical Committee of "Regione Calabria, sezione Area Centro" (identifier: 67/D.G. 18.02.2021), in accordance with the latest version of the Declaration of Helsinki [21].

\section{Measures}

A triphasic procedure was applied for the item generation of the EBA-O. The research team built a provisional form starting from existing questionnaires assessing eating behaviors, and validated in Italian (i.e., Binge Eating Scale [16, 22]; Yale Food Addiction Scale 2.0 [13, 18]; Grazing 
Questionnaire [19, 23]; Night Eating Questionnaire [17, 24]), and from content descriptions across literature for those not available in Italian or not already addressed in questionnaires (i.e., prandial hyperphagia, social eating, emotional eating, orthorexia, restriction and fasting). A content validity analysis was performed by three experts in the field of eating disorders and nutrition in obesity, who checked for the quality, accuracy, and appropriateness of the contents. A qualitative face validity analysis was run to improve the quality of the contents in the real world; 15 patients from the target population (with obesity) were encouraged to describe their eating behaviors, their experiences, and the areas of distress within the nutrition, and to review the items. Finally, the response categories were adapted towards the usability of the EBA-O as a screening tool. The initial version consisted of 36 items on an 8-point Likert scale ranging from 0 (never) to 7 (everyday).

\section{Statistical analysis}

Statistical analysis was performed with JASP open-source software (JASP, version 0.13.1, University of Amsterdam, The Netherlands). Data are presented as means, standard deviations (SD), frequencies and percentages.

Exploratory factor analysis (EFA) with principal axis factoring method was chosen to investigate the factor structure of the EBA-O. We used the Kaiser-Meyer-Olkin's (KMO) coefficient and Bartlett's test to determine how suited data for EFA. The parallel analysis method was used to determine the number of factors to extract. We chose the oblique oblimin rotation because the factors were expected to be correlated. Factor loadings $>0.40$ were considered meaningful. Finally, given the renown limitations to the use of the Cronbach's a [25, 26], due to the very restrictive assumptions it relies on, we assessed internal consistency through the McDonald' $\omega$ total [27].

\section{Results}

The final sample included 421 participants: 337 females (80\%). Table 1 describes the demographics.

\section{Item reduction analysis}

The items that either loaded less than $<0.40$ on their respective factor or that cross-loaded substantially across factors through EFA were removed. Eighteen items regarding emotional eating, grazing, social eating, orthorexia, fasting and restriction (3 items each) were discarded, leaving 18 items for the final version of the EBA-O (Table 2).
Table 1 Demographic data of the samples

\begin{tabular}{|c|c|c|c|c|c|c|}
\hline & \multicolumn{2}{|c|}{ Study 1} & \multicolumn{2}{|c|}{ Study 2} & \multicolumn{2}{|c|}{ Study 3} \\
\hline & $\mathrm{Fr}$ & $\%$ & $\mathrm{Fr}$ & $\%$ & $\mathrm{Fr}$ & $\%$ \\
\hline $\mathrm{Age}^{\mathrm{a}}$ & 27.4 & 12.9 & 33.4 & 15.8 & 38.8 & 13.6 \\
\hline Body mass index ${ }^{a}$ & 23.2 & 4.7 & 34.4 & 4.5 & 38.8 & 11.2 \\
\hline \multicolumn{7}{|l|}{ Sex } \\
\hline Female & 337 & 80 & 110 & 65 & 62 & 84 \\
\hline Male & 84 & 20 & 59 & 35 & 12 & 16 \\
\hline \multicolumn{7}{|l|}{ Education } \\
\hline Middle school I & 96 & 23 & 37 & 22 & 19 & 26 \\
\hline High school II & 184 & 44 & 68 & 40 & 42 & 57 \\
\hline University degree & 141 & 33 & 64 & 38 & 13 & 17 \\
\hline \multicolumn{7}{|l|}{ Occupation } \\
\hline Housewife & 10 & 3 & 5 & 3 & 5 & 7 \\
\hline Unemployed & 17 & 4 & 10 & 6 & 20 & 27 \\
\hline Employed & 118 & 28 & 73 & 43 & 34 & 46 \\
\hline Retired & 5 & 1 & 3 & 2 & 2 & 3 \\
\hline Student & 271 & 64 & 78 & 46 & 13 & 17 \\
\hline \multicolumn{7}{|l|}{ Civil status } \\
\hline Single & 300 & 71 & 112 & 66 & 27 & 37 \\
\hline Married & 106 & 25 & 49 & 29 & 46 & 62 \\
\hline Separated/divorced & 11 & 3 & 3 & 2 & 1 & 1 \\
\hline Widower & 4 & 1 & 5 & 3 & 0 & 0 \\
\hline
\end{tabular}

${ }^{\text {a }}$ Results are presented as means and (SD) 
Table 2 Italian version of the Eating Behaviors Assessment for Obesity (EBA-O)

\begin{tabular}{|c|c|c|c|c|c|c|c|c|}
\hline NEGLI ULTIMI 3 MESI & Mai & $\begin{array}{l}\text { Meno di } \\
1 \text { volta al } \\
\text { mese }\end{array}$ & $\begin{array}{l}1 \\
\text { volta al mese }\end{array}$ & $\begin{array}{l}2-3 \\
\text { volte al } \\
\text { mese }\end{array}$ & $\begin{array}{l}1 \text { volta } \\
\text { alla settimana }\end{array}$ & $\begin{array}{l}2-3 \text { volte } \\
\text { alla setti- } \\
\text { mana }\end{array}$ & $\begin{array}{l}4-6 \text { volte } \\
\text { alla } \\
\text { settimana }\end{array}$ & Ogni giorno \\
\hline $\begin{array}{l}\text { 1. Ti è capitato di alzarti durante la notte } \\
\text { e di sentire il desiderio di mangiare } \\
\text { qualcosa? }\end{array}$ & O & O & O & ○ & O & ○ & O & O \\
\hline $\begin{array}{l}\text { 2. In caso di risvegli notturni, ti è capitato } \\
\text { di non riuscire a riaddormentarti senza } \\
\text { mangiare qualcosa? }\end{array}$ & O & O & O & O & O & O & O & O \\
\hline $\begin{array}{l}\text { 3. Ti è capitato di mangiare qualcosa dopo } \\
\text { cena per dormire meglio? }\end{array}$ & O & O & O & O & O & O & O & O \\
\hline $\begin{array}{l}\text { 4. Ti è capitato di non riuscire a dormire } \\
\text { se non mangi qualcosa prima di andare } \\
\text { a letto, anche dopo aver fatto una cena } \\
\text { normale? }\end{array}$ & O & O & O & ○ & O & ○ & O & O \\
\hline $\begin{array}{l}\text { 5. Ti è capitato di avvertire il desiderio } \\
\text { impellente di mangiare certi cibi ad alto } \\
\text { contenuto di carboidrati/grassi e di non } \\
\text { riuscire a pensare ad altro? }\end{array}$ & O & O & O & O & O & O & O & O \\
\hline $\begin{array}{l}\text { 6. Hai fatto di tutto per procurarti questi } \\
\text { cibi, pur avendo altri cibi disponibili, } \\
\text { quando hai sentito questo impulso? }\end{array}$ & 0 & 0 & 0 & O & O & 0 & 0 & 0 \\
\hline $\begin{array}{l}\text { 7. Ti è capitato di non riuscire a fermarti } \\
\text { e aver continuato a mangiare questi cibi, } \\
\text { nonostante sapessi che fossero dannosi per } \\
\text { la salute? }\end{array}$ & O & O & O & ○ & O & ○ & O & O \\
\hline $\begin{array}{l}\text { 8. Hai provato a ridurre o smettere di man- } \\
\text { giare questi cibi, senza riuscirci? }\end{array}$ & O & O & O & O & O & O & O & O \\
\hline $\begin{array}{l}\text { 9. Ti sei sentito irritabile/nervoso/triste } \\
\text { o hai avuto sintomi fisici (es. mal di } \\
\text { testa, stanchezza) quando hai ridotto o } \\
\text { smesso di mangiare questi cibi e hai avuto } \\
\text { bisogno di mangiarli per stare meglio? }\end{array}$ & O & O & O & O & O & O & O & O \\
\hline 10. Sei stato goloso di cibi dolci? & 0 & 0 & 0 & 0 & 0 & 0 & 0 & 0 \\
\hline $\begin{array}{l}\text { 11. Hai consumato frequentemente cibi } \\
\text { dolci e/o bevande zuccherate? }\end{array}$ & $\mathrm{O}$ & O & O & ○ & O & ○ & O & O \\
\hline $\begin{array}{l}\text { 12. Hai avuto un forte desiderio di man- } \\
\text { giare dolci o bere bevande zuccherate se } \\
\text { ansioso o triste? }\end{array}$ & O & O & O & O & O & O & O & O \\
\hline $\begin{array}{l}\text { 13. Rispetto agli altri commensali, le tue } \\
\text { porzioni di cibo sono molto più abbon- } \\
\text { danti? }\end{array}$ & $\mathrm{O}$ & O & O & O & ○ & O & O & O \\
\hline $\begin{array}{l}\text { 14. Ti è capitato di fare spesso il "bis" } \\
\text { durante i pasti principali? }\end{array}$ & O & O & O & O & 0 & 0 & 0 & 0 \\
\hline $\begin{array}{l}\text { 15. Hai mangiato troppo, ma soltanto } \\
\text { durante i pasti principali? }\end{array}$ & 0 & 0 & 0 & 0 & 0 & 0 & 0 & 0 \\
\hline $\begin{array}{l}\text { 16. Ti è capitato di mangiare, in un deter- } \\
\text { minato periodo di tempo, rapidamente e } \\
\text { fino a sentirti spiacevolmente pieno/a, una } \\
\text { quantità di cibo significativamente mag- } \\
\text { giore di quella che la maggior parte delle } \\
\text { persone mangerebbe nello stesso tempo e } \\
\text { in circostanze simili? }\end{array}$ & 0 & 0 & 0 & 0 & 0 & 0 & 0 & 0 \\
\hline $\begin{array}{l}\text { 17. Hai avuto la sensazione di perdere il } \\
\text { controllo, e di non riuscire a controllare } \\
\text { cosa, quanto mangiare e quando smettere? }\end{array}$ & 0 & 0 & 0 & 0 & 0 & 0 & 0 & 0 \\
\hline $\begin{array}{l}\text { 18. Hai provato vergogna o senso di colpa a } \\
\text { causa di questo comportamento? }\end{array}$ & 0 & 0 & 0 & 0 & 0 & 0 & 0 & 0 \\
\hline
\end{tabular}


Table 2 (continued)

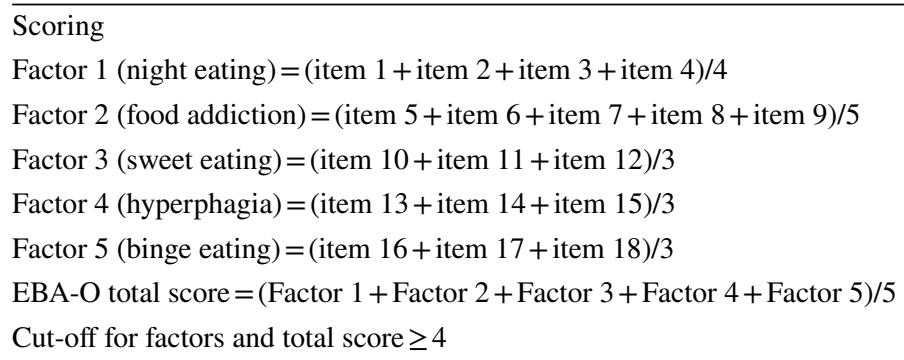

\section{Exploratory factor analysis}

The KMO's coefficient (0.91) and the Bartlett test $\left(\chi^{2}(153)=5283.66, p<0.001\right)$ indicated that the data were appropriate for EFA. A five-factor structure explaining $68.3 \%$ of the variance was obtained. Table 3 shows the factor loadings of each item. The first factor $(19.3 \%$ of the variance) consisted of five questions evaluating food addiction; the second factor $(13.7 \%$ of the variance) included four items evaluating post-dinner eating and night eating; the third factor (13.6\% of the variance) comprised three questions that assessed binge eating; the fourth factor included three questions that examined sweet eating (11.8\% of the variance) and the last

Table 3 Factor loadings of each EBA-O item and McDonald's $\omega$

\begin{tabular}{|c|c|c|c|c|c|}
\hline & $\begin{array}{l}\text { Factor } 1 \\
\text { Food addiction }\end{array}$ & $\begin{array}{l}\text { Factor } 2 \\
\text { Night eating }\end{array}$ & $\begin{array}{l}\text { Factor } 3 \\
\text { Binge eating }\end{array}$ & $\begin{array}{l}\text { Factor } 4 \\
\text { Sweet eating }\end{array}$ & $\begin{array}{l}\text { Factor } 5 \\
\text { Hyperphagia }\end{array}$ \\
\hline $\begin{array}{l}\text { 1. Have you ever got up during the night and felt the desire to eat } \\
\text { something? }\end{array}$ & & 0.776 & & & \\
\hline $\begin{array}{l}\text { 2. In case of nocturnal awakenings, have you ever been unable to go } \\
\text { back to sleep without eating something? }\end{array}$ & & 0.781 & & & \\
\hline 3. Have you ever had something to eat after dinner to sleep better? & & 0.633 & & & \\
\hline $\begin{array}{l}\text { 4. Have you ever been unable to sleep if you did not eat something } \\
\text { before going to bed, even after having a normal dinner? }\end{array}$ & & 0.731 & & & \\
\hline $\begin{array}{l}\text { 5. Have you ever felt the urge to eat certain foods that are high in } \\
\text { carbohydrates/fats and cannot think of anything else? }\end{array}$ & 0.738 & & & & \\
\hline $\begin{array}{l}\text { 6. Did you go out of your way to get these foods, despite having other } \\
\text { foods available, when you felt this urge? }\end{array}$ & 0.762 & & & & \\
\hline $\begin{array}{l}\text { 7. Have you ever been unable to stop and have continued to eat these } \\
\text { foods, even though you knew they were harmful to your health? }\end{array}$ & 0.899 & & & & \\
\hline 8. Have you tried to reduce or stop eating these foods and failed? & 0.814 & & & & \\
\hline $\begin{array}{l}\text { 9. Did you feel irritable/nervous/sad or had physical symptoms (head- } \\
\text { ache, fatigue) when you reduced or stopped eating these foods and } \\
\text { needed to eat them to get better? }\end{array}$ & 0.601 & & & & \\
\hline 10. Have you been greedy for sweet foods? & & & & 0.878 & \\
\hline 11. Have you frequently consumed sweet foods and/or sugary drinks? & & & & 0.884 & \\
\hline $\begin{array}{l}\text { 12. Have you had a strong desire to eat sweets or sugary drinks if you } \\
\text { are anxious or sad? }\end{array}$ & & & & 0.558 & \\
\hline 13. Are your portions much larger compared to other diners? & & & & & 0.776 \\
\hline 14. Do you often have an "encore" during main meals? & & & & & 0.771 \\
\hline 15. Have you eaten too much but only during the main meals? & & & & & 0.691 \\
\hline $\begin{array}{l}\text { 16. Have you eaten, over a period of time, quickly and until you feel } \\
\text { uncomfortably full, significantly more food than most people would } \\
\text { eat at the same time and under similar circumstances? }\end{array}$ & & & 0.633 & & \\
\hline $\begin{array}{l}\text { 17. If so, did you feel like you were losing control and not being able } \\
\text { to control what, how much to eat and when to stop? }\end{array}$ & & & 1.000 & & \\
\hline 18. Have you felt ashamed or guilty because of this behavior? & & & 0.781 & & \\
\hline McDonald's $\omega$ & 0.92 & 0.85 & 0.92 & 0.87 & 0.80 \\
\hline
\end{tabular}


factor included three items that evaluated hyperphagia (9.9\% of the variance). Thus, factors were, respectively, renamed as "food addiction", "night eating", "binge eating", "sweet eating"; and "hyperphagia". The factors were highly correlated with each other. The highest correlation was between factors 1 and 3 and the lowest between factors 2 and 4 (Table 4). Factors and total score means are displayed in Fig. 1.

\section{Internal consistency (McDonald's $\omega$ )}

The McDonald's coefficient $\omega$ was very high for all factors indicating very good reliability: food addiction $=0.92 ;$ night eating $=0.85$; binge eating $=0.92$; sweet eating $=0.87$; and hyperphagia $=0.80($ Table 2$)$.

\section{Study 2: confirmatory factor analysis and convergent validity of the EBA-O}

\section{Participants}

After the completion of the first phase, the second study was conducted to examine the factor structure and the convergent validity of the EBA-O through a second online survey posted on Facebook recruiting a sample of individuals with obesity. Inclusion criteria were men and women, aged 18-65 years, and BMI $\geq 30 \mathrm{~kg} / \mathrm{m}^{2}$. Participants were informed about the purpose of the study, the procedures, the voluntary nature of participation, the anonymity, management, and retention of data. Overall, 169 people, of whom 110 females (65\%), agreed to participate by clicking on the consent box and then completed the battery of measures. The Ethical Committee
Table 4 Correlations between factors of the EBA-O

\begin{tabular}{lccccc}
\hline & Factor 1 & Factor 2 & Factor 3 & Factor 4 & Factor 5 \\
\hline Factor 1 Food addiction & - & & & & \\
Factor 2 Night eating & $0.528^{* * *}$ & - & & \\
Factor 3 Binge eating & $0.778^{* * *}$ & $0.423 * * *$ & - & & \\
Factor 4 Sweet eating & $0.571 * * *$ & $0.355^{* * *}$ & $0.459 * * *$ & - & \\
Factor 5 Hyperphagia & $0.402 * * *$ & $0.456^{* * *}$ & $0.461 * * *$ & $0.451^{* * *}$ & - \\
\hline
\end{tabular}

$* * * p<0.001$

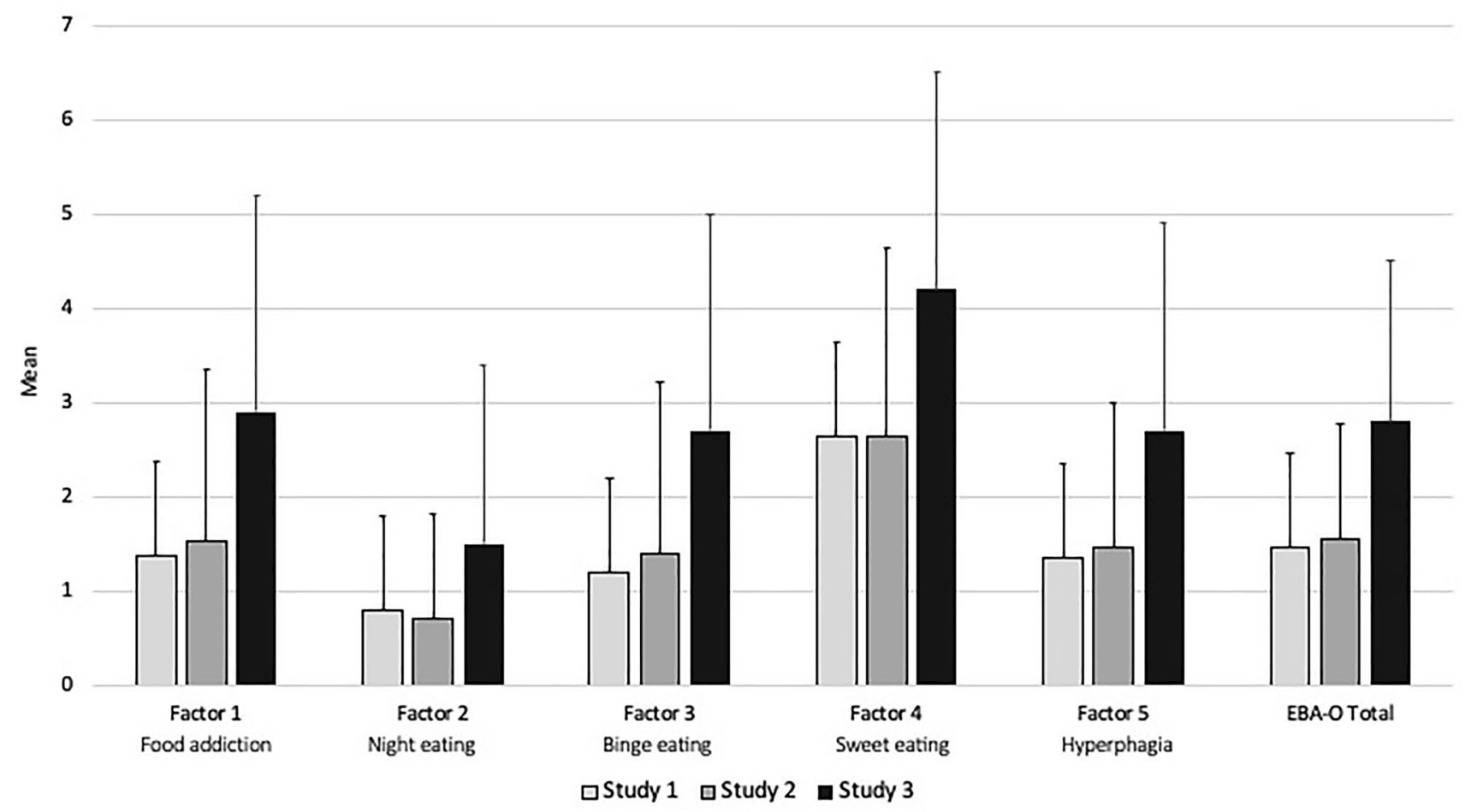

Fig. 1 Means and standard deviation of EBA-O factors and total score in study 1,2 and 3 
of "Regione Calabria, sezione Area Centro" approved the study protocol (identifier: 67/D.G. 18.02.2021), in accordance with the latest version of the Declaration of Helsinki [14].

\section{Measures}

To assess the convergent validity, participants completed the following test battery in addition to the EBA-O: the Binge Eating Scale (BES) $[16,22]$ is a 16 -item test that measures the binge severity; scores of $<17,17-27$ and $>27$ indicate that the risk of an individual having BED is unlikely, possible and probable, respectively. The Night Eating Questionnaire (NEQ) $[17,24]$ is made up of 14 items that evaluate the night eating behavior through 4 dimensions (i.e., morning anorexia, evening hyperphagia, mood/sleep, and nocturnal ingestions); a score of 30 is strongly suggestive of Night Eating Syndrome. The Grazing Questionnaire (GQ) $[19,23]$ consists of 8 items that account for two dimensions (i.e., grazing behavior and controllability) and higher scores reflect a greater degree of grazing behaviors and cognitions. Finally, the Yale Food Addiction Scale 2.0 (YFAS 2.0) $[13,18]$, that assesses addiction-like eating behavior over the past 12 months through 35 items, scored on an 8-point scale ranging from never $($ score $=0)$ to every day $($ score $=7$ ) accounting for 11 symptoms. We used the validated Italian versions of all four tests; McDonald's $\omega$ were, respectively, 0.87, 0.69, and 0.82 for BES, NEQ, and GQ. Kuder-Richardson's alpha for YFAS 2.0 was 0.86 .

\section{Statistical analysis}

As factors resulted highly correlated in study 1, a secondorder confirmatory factor analysis (CFA) was carried out to test the factor structure with JASP open-source software (JASP, Version 0.13.1, University of Amsterdam, The Netherlands), to examine the best latent structure of the EBA-O and to confirm the appropriateness of a total score.

The relative chi-square $\left(\chi^{2} / d f\right)$, the Tucker-Lewis Index (TLI), the Comparative Fit Index (CFI), the Root Mean Square Error of Approximation (RMSEA), and the Standardized Root Mean Squared Residual (SRMR) were used to assess the goodness of fit of data to a proposed model. For TLI and CFI, values of 0.90 and above were considered adequate, whereas values of 0.95 or above were considered very good; for RMSEA values of 0.08 and below was considered adequate and 0.05 or less very good; for SRMR a cut-off value close to.08 was considered adequate. Values of $\chi^{2} / d f<3.0$ are good and those $<2.0$ are very good. The levels of these indices were evaluated according to the recommendations of $\mathrm{Hu}$ and Bentler [28].

Construct validity was determined by correlations between the factors of the EBA-O and the respective questionnaires, considering that correlation coefficients $(r)$ greater than 0.30 are recommended [29].

\section{Results}

\section{Confirmatory factorial analysis}

The second-order factor model showed an adequate fit: $\mathrm{CFI}=0.93$, TLI $=0.92, \mathrm{RMSEA}=0.08$, relative chi-square $\left(\chi^{2} / d f\right)=1.95$ and SRMR $=0.07$, suggesting the suitability of the EBA-O model (Fig. 2). This finding suggests that the use of a total score from the EBA-O is appropriate.

Factors and total score means are displayed in Fig. 1.

\section{Convergent validity}

The correlations between the EBA-O factors and psychopathological questionnaires showed significant positive correlations between factors 1, 2, 3 and 4. Instead, factor 5 (hyperphagia) did not show any significant correlation with the other factors (Table 5).

\section{Study 3: clinical use of the EBA-O}

This study aimed to test the EBA-O in a clinical sample of patients with obesity.

\section{Participants}

A clinical sample of patients with obesity was recruited to test the capability of the EBA-O to characterize altered eating behaviors in a clinical setting. Participants were retrieved from patients referred for the treatment of obesity at the University Hospital Mater Domini of Catanzaro in the previous 18 months (form January 2020 to June 2021). We set the following inclusion criteria: male and female patients, aged $18-65$ years, and BMI $\geq 30 \mathrm{~kg} / \mathrm{m}^{2}$. Patients were considered ineligible in case of clinically diagnosed dementia, diagnosis of intellectual disability from mild to severe according to DSM-5 (corresponding to IQ $<70$ ), or conditions that did not allow the completion of the assessment (e.g., language problems, dyslexia, or poor knowledge of the Italian language). Patients were contacted by email/phone, informed about the purpose and the procedures of the study, the voluntary nature of participation in the study and the management, and retention of data.

\section{Measures}

All patients completed in addition to the EBA-O the validated Italian version of the YFAS-2.0 [13, 18], the NEQ [17, 
Fig. 2 Path diagram of the second-order five-factor model of the EBA-O with reported standardized coefficients of first- and second-order loadings. All values are significant for $p<0.001$

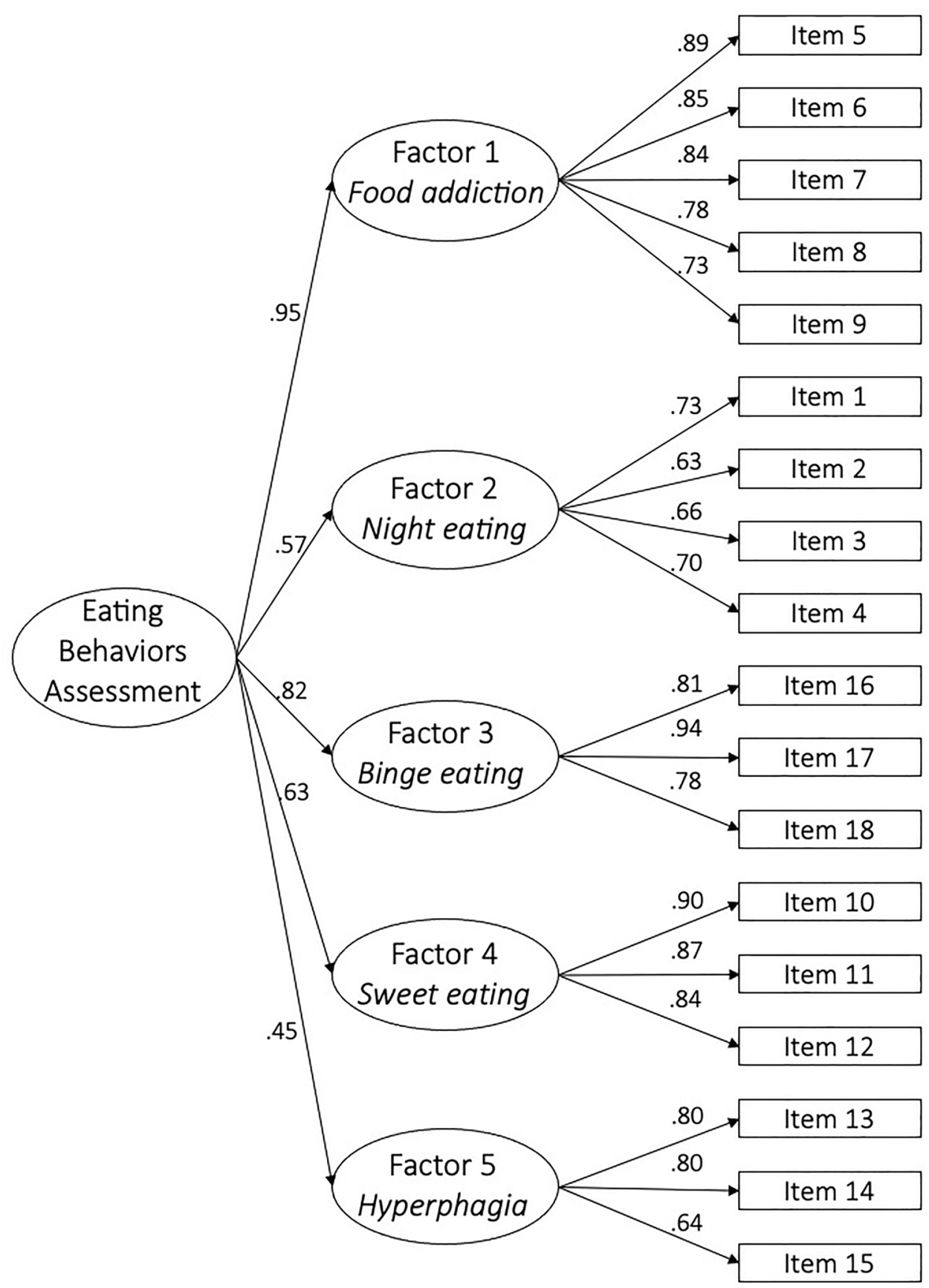

Table 5 Results of convergent validity

\begin{tabular}{|c|c|c|c|c|c|}
\hline & $\begin{array}{l}\text { Factor } 1 \\
\text { Food addiction }\end{array}$ & $\begin{array}{l}\text { Factor } 2 \\
\text { Night eating }\end{array}$ & $\begin{array}{l}\text { Factor } 3 \\
\text { Binge eating }\end{array}$ & $\begin{array}{l}\text { Factor } 4 \\
\text { Sweet eating }\end{array}$ & $\begin{array}{l}\text { Factor } 5 \\
\text { Hyperphagia }\end{array}$ \\
\hline BES & $0.570 * * *$ & 0.230 & $0.524 * * *$ & $0.511 * * *$ & 0.022 \\
\hline GQ & $0.477 * * *$ & $0.323 * *$ & $0.568 * * *$ & $0.542 * * *$ & 0.125 \\
\hline I-NEQ & 0.261 & $0.452 * *$ & 0.106 & 0.116 & -0.137 \\
\hline I-YFAS 2.0 & $0.553 * * *$ & 0.068 & $0.615 * * *$ & $0.514 * * *$ & 0.211 \\
\hline
\end{tabular}

BES Binge Eating Scale, GQ Grazing Questionnaire, I-NEQ Italian Night Eating Questionnaire, I-YFAS 2.0 Italian Yale Food Addiction Scale 2.0

Significant results are in bold characters. $* * * p<0.001 ; * * p<0.01 ; * p<0.05$ 
24], the BES [16, 22] and the Eating Disorder ExaminationQuestionnaire (EDE-Q) [30, 31].

\section{Statistical analysis}

Multivariate Analysis of Variance (MANOVA) was carried out with the five factors of EBA-O as independent variables and YFAS-2.0, BES and NEQ as dependent variables. Eta-squared $\left(\eta^{2}\right)$ was used as a measure of the effect size of MANOVA considering values of 0.01, 0.06, and 0.14 as indicating small, medium, and large effects, respectively. The Bonferroni correction was used to correct for multiple comparisons $(p=0.05 / 15=0.003)$ (SPSS; IBM SPSS Statistics, version 21.0). Finally, a Student's $t$ test was applied to test the differences in EDE-Q and EBA-O total score according to a cut-off suggested by the authors (EBA-O $\geq 4$ ). Considering that a behavior that occurs with at least weekly frequency is clinically significant (e.g., binge eating in DSM-5), this threshold would correspond with the score 4 in the EBA-O; thus, the authors agreed in proposing a score $\geq 4$ as a cut-off both for the single factors and for the total score of the EBA-O.

Cohen's $d$, a measure of standardized effect size, was calculated considering that values of $0.2,0.5,0.8$, respectively, indicate small, medium and large effect sizes [32].

\section{Results}

Overall, 74/109 (69\%), mean age $38.8 \pm 13.6$ and BMI $38.8 \pm 11.2$, of whom 62 women $(84 \%)$ consented to participate (Table 1).

Findings from MANOVA revealed significant associations between factor 1 and YFAS-2.0 $(F=22.954 ; p<0.001$; $\left.\eta^{2}=0.310\right)$, factor 2 and NEQ $(F=51.462 ; p<0.001$; $\left.\eta^{2}=0.502\right)$, and factor 3 and $\operatorname{BES}(F=18.572 ; p<0.001$; $\left.\eta^{2}=0.267\right)$.

Patients with an EBA-O total score $\geq 4$ reported significantly higher EDE-Q total score $(3.7 \pm 0.8)$ than patients with EBA-O total score $<4(2.9 \pm 1.2)(t=2.612, p=0.011$, $d=0.7)$.

\section{General discussion}

Eating disorders and disordered eating behaviors are associated with obesity, impacting on treatment response, and causing long-term adverse consequences; thus, assessing them becomes relevant in the clinical practice. To date, the screening of these behaviors is entrusted to specialized figures in the field of eating disorders and obesity, and requires the use of multiple tests that make the evaluation long. As an easy-to-use screening tool assessing eating behaviors in obesity is still missing, the current study aimed to develop (study 1), validate (study 2) and test (study 3 ) the EBA-O, a new instrument designed to identify and characterize eating behaviors of individuals with obesity. This instrument was designed to assess different pathological eating behaviors as a single easy-to-use tool also for clinicians without expertise in eating disorders. The results of exploratory and confirmatory factor analyses supported a final 18 -item and a second-order 5-factor structure of the EBA-O, in either population-based or clinical samples. The model explained over the half of the variance in the general population and showed evidence for an optimal suitability in a sample of patients with obesity.

"Food addiction", "night eating," and "binge eating" accounted for most of the variance, hence representing the core features of the EBA-O. This may be conceptually justifiable considering that several studies on general population report food addiction, night eating and binge eating as the most frequent and interrelated eating behaviors [33-35].

As a result of the factorial analysis, some eating behaviors (i.e., grazing, emotional eating, social eating, orthorexia, restriction, fasting) were dropped out from the final version. A possible reason for the exclusion may lie on the content similarities some items share (i.e., grazing with binge eating, social eating with prandial hyperphagia, emotional eating with binge eating). Authors hypothesize that some items might have loaded closely to the other ones that EFA identified as the most significant. Besides, there is not a definite clinical conceptualization for some eating behaviors (i.e. grazing, orthorexia) [12, 36, 37], and clinicians and researchers have pointed out that current existing measures of emotional eating may be distorted by one's current emotional state or may measure a different construct than intended [38].

Construct validation with the available instruments for disordered eating behaviors provided evidence for the convergent validity of the EBA-O. The factors of EBA-O correlated positively with the other psychopathological questionnaires examining pathological eating behaviors. Only hyperphagia did not correlate with the psychometric scores for pathological eating behaviors. For this reason, it could be hypothesized that hyperphagia may characterize the "healthy" patients with obesity and play a role in making a differential diagnosis in the panorama of emotionally related eating behaviors.

Lastly, the investigation of eating behaviors in a clinical sample seeking treatment for obesity indicated a good discriminant validity of the EBA-O. The MANOVA demonstrated the capability of factors 1,2 and 3 to capture pathological scores of YFAS-2.0, NEQ and BES, respectively, thus indicating the good reliability of the EBA-O.

An increasing trend in all factors means was observed from study 1 to study 3 (Fig. 1), further demonstrating the capability of the EBA-O to capture diversity across the 
"healthy"-"pathological" spectrum. Within the factors, sweet eating reached the highest means in all studies; conversely, night eating scored the lowest.

Given the lack of validated instruments in Italian for sweet eating and hyperphagia, it was not possible to calculate the cut-offs for each factor and a total EBA-O score. However, a statistical criterion is not necessary to establish a minimum severity threshold, considering that a dysfunctional behavior that occurs once a week is already considered clinically relevant. For this reason, authors chose to evaluate the association between the EBA-O total score $\geq 4$ (corresponding to dysfunctional eating behaviors that occur once a week) and the total score for eating psychopathology (EDE-Q). The result seems to support the advice to consider scores $\geq 4$ for the EBA-O total score as suggestive of a possible eating disorder and factors scoring $\geq 4$ as indicative of altered eating behaviors. Future investigations with larger clinical samples should evaluate the accuracy of this threshold.

Taken together, the study provides preliminary indications on the sensitivity and usefulness of the EBA-O in catching emotionally related eating behaviors. Furthermore, the EBA-O guarantees a very intuitive approach, making it easier to be administered and interpreted by clinicians who are not specialized in the field of eating disorders.

Accordingly, this tool fits with the actual aim of screening patients with obesity at risk for eating disorders who should be referred to more specialized settings and would benefit from an integrated approach (i.e., nutritional, medical, psychological, pharmacological).

Before reaching the conclusions, the authors want to acknowledge strengths and limits of this research. The main strength of this study lies in the tripartite design that allowed, in a different but consecutive way, to develop, validate and test a new measure that has shown its validity and usefulness in the clinical practice. The item development took into account either experts' or the target population's opinion, enabling a more accurate and understandable description of eating behaviors. The authors admit the small sample size for study 3; unfortunately, the limitations of access to clinics during the quarantine due to the COVID-19 emergency explain the sample shortage that only future research will solve. Although samples from study 1 and 2 spanned across different ages and men were included, we acknowledge that age- and gender-related issues should be kept in mind when assessing eating behaviors. Some eating behaviors, such as restriction and fasting, might be overrepresented in adolescence and binge-purge more common through the adulthood span $[39,40]$. Furthermore, some dysfunctional eating behaviors result predominant in women (i.e. binge eating, food addiction), and male gender was underrepresented in all three studies. This fact closely resembles the real world, not only because obesity is more frequent among females, but also because women tend to participate more than men in studies in the psychological field [41]. However, a bias in the structural analysis cannot be excluded. Given that such developmental and gender-related perspective may have different related implications for the assessment and the treatment, further investigations with stratified samples are encouraged. Finally, we did not run a re-test, making it difficult to understand if the EBA-O is a stable eating behavior measure; but, as a matter of fact, the EBA-O is proposed as a state and not as a trait measure.

\section{Conclusions}

The psychometric properties of the EBA-O support this instrument as a high-quality, reliable and easy-to-use screening tool in the clinical practice, especially for clinicians without expertise in eating disorders. If we are to prevent treatment relapse and dropouts, the screening of pathological eating behaviors could guide clinicians dealing with obesity in tailoring treatments according to eating behaviors and in referring patients at higher risk for eating disorders to specialized eating disorders units.

\section{What is already known on this subject?}

Pathological eating behaviors may drive to phenotype obese patients. To date, there is no available specific assessment to evaluate pathological eating behaviors in obesity.

\section{What does this study add?}

The EBA-O is a self-report measure developed to identify emotional-related eating behaviors among patients with obesity. It has proven to be a valuable, reliable and feasible tool for clinicians, also without expertise in the field of eating disorders.

Acknowledgements We thank all participants and patients who agreed to participate in our study.

Funding No funding was received for this research.

Availability of data and materials Data are available from the corresponding author upon request.

\section{Declarations}

Conflict of interest On behalf of all authors, the corresponding author states that there is no conflict of interest.

Ethical approval All procedures performed in studies involving human participants were in accordance with the ethical standards of institutional and/or national research committees and with the 1964 Helsinki Declaration and its later amendments or comparable ethical standards. 
Informed consent Informed consent was obtained from all individual participants included in the study.

\section{References}

1. The Lancet Gastroenterology \& Hepatology (2021) Obesity: another ongoing pandemic. Lancet Gastroenterol Hepatol 6:411. https://doi.org/10.1016/S2468-1253(21)00143-6

2. World health Organization (2021) Obesity. https://www.who.int/ news-room/facts-in-pictures/detail/6-facts-on-obesity. Accessed 26 Oct 2021

3. Carbone EA, Caroleo M, Rania M et al (2021) An open-label trial on the efficacy and tolerability of naltrexone/bupropion SR for treating altered eating behaviours and weight loss in binge eating disorder. Eat Weight Disord Stud Anorex Bulim Obes 26:779-788. https://doi.org/10.1007/s40519-020-00910-x

4. Grilo CM, Lydecker JA, Morgan PT, Gueorguieva R (2021) Naltrexone + bupropion combination for the treatment of bingeeating disorder with obesity: a randomized, controlled pilot study. Clin Ther 43:112-122.e1. https://doi.org/10.1016/j.clinthera.2020. 10.010

5. Oppert J-M, Bellicha A, Ciangura C (2021) Physical activity in management of persons with obesity. Eur J Intern Med 93:8-12. https://doi.org/10.1016/j.ejim.2021.04.028

6. Segura-Garcia C, Rania M, Carbone EA et al (2021) Naturalistic and uncontrolled pilot study on the efficacy of vortioxetine in binge eating disorder with comorbid depression. Front Psychiatry. https://doi.org/10.3389/fpsyt.2021.635502

7. Cornejo-Pareja I, Molina-Vega M, Gómez-Pérez AM et al (2021) Factors related to weight loss maintenance in the medium-long term after bariatric surgery: a review. J Clin Med 10:1739. https:// doi.org/10.3390/jcm10081739

8. Ivezaj V, Carr MM, Brode C et al (2021) Disordered eating following bariatric surgery: a review of measurement and conceptual considerations. Surg Obes Relat Dis 17:1510-1520. https://doi. org/10.1016/j.soard.2021.03.008

9. Kyrou I, Randeva HS, Tsigos C et al (2018) Clinical problems caused by obesity. In: Feingold KR, Anawalt B, Boyce A et al (eds) Endotext. MDText.com, Inc.; 2000, South Dartmouth

10. Succurro E, Segura-Garcia C, Ruffo M et al (2015) Obese patients with a binge eating disorder have an unfavorable metabolic and inflammatory profile. Medicine (Baltim) 94:e2098. https://doi.org/ 10.1097/MD.0000000000002098

11. American Association Psychiatric (2013) Diagnostic and Statistical Manual of Mental Disorders (DSM-5®), 5th edn. American Psychiatric Association, Arlington

12. Conceição EM, Mitchell JE, Engel SG et al (2014) What is "grazing"? Reviewing its definition, frequency, clinical characteristics, and impact on bariatric surgery outcomes, and proposing a standardized definition. Surg Obes Relat Dis 10:973-982. https://doi. org/10.1016/j.soard.2014.05.002

13. Aloi M, Rania M, Rodríguez Muñoz RC et al (2017) Validation of the Italian version of the Yale Food Addiction Scale 2.0 (I-YFAS 2.0) in a sample of undergraduate students. Eat Weight Disord Stud Anorex Bulim Obes 22:527-533. https://doi.org/10.1007/ s40519-017-0421-x

14. Rania M, de Filippis R, Caroleo M et al (2021) Pathways to orthorexia nervosa: a case series discussion. Eat Weight Disord Stud Anorex Bulim Obes 26:1675-1683. https://doi.org/10.1007/ s40519-020-00948-x

15. Caroleo M, Primerano A, Rania M et al (2018) A real world study on the genetic, cognitive and psychopathological differences of obese patients clustered according to eating behaviours. Eur
Psychiatry 48:58-64. https://doi.org/10.1016/j.eurpsy.2017.11. 009

16. Gormally J, Black S, Daston S, Rardin D (1982) The assessment of binge eating severity among obese persons. Addict Behav 7:47-55

17. Allison KC, Lundgren JD, O'Reardon JP et al (2008) The Night Eating Questionnaire (NEQ): psychometric properties of a measure of severity of the Night Eating Syndrome. Eat Behav 9:62-72. https://doi.org/10.1016/j.eatbeh.2007.03.007

18. Gearhardt AN, Corbin WR, Brownell KD (2016) Development of the Yale Food Addiction Scale version 2.0. Psychol Addict Behav 30:113-121. https://doi.org/10.1037/adb0000136

19. Lane B, Szabó M (2013) Uncontrolled, repetitive eating of small amounts of food or 'grazing': development and evaluation of a new measure of atypical eating. Behav Change 30:57-73. https://doi.org/10.1017/bec.2013.6

20. van den Heuvel M, Hörchner R, Wijtsma A et al (2011) Sweet eating: a definition and the development of the Dutch sweet eating questionnaire. Obes Surg 21:714-721. https://doi.org/ 10.1007/s11695-010-0094-2

21. World Medical Association (2013) World Medical Association Declaration of Helsinki: ethical principles for medical research involving human subjects. JAMA 310:2191. https://doi.org/10. 1001/jama.2013.281053

22. Ricca V, Mannucci E, Moretti S et al (2000) Screening for binge eating disorder in obese outpatients. Compr Psychiatry 41:111115. https://doi.org/10.1016/S0010-440X(00)90143-3

23. Aloi M, Rania M, De Fazio P, Segura-García C (2017) Italian validation of the Grazing Questionnaire: analysis of psychometric properties. Minerva Psichiatr 58:196-202. https://doi.org/10. 23736/S0391-1772.17.01948-3

24. Aloi M, Rania M, De Fazio P et al (2017) Validation of the Italian version of the Night Eating Questionnaire (I-NEQ). J Psychopathol 23:137-144

25. McNeish D (2018) Thanks coefficient alpha, we'll take it from here. Psychol Methods 23:412-433. https://doi.org/10.1037/ met0000144

26. Trizano-Hermosilla I, Alvarado JM (2016) Best alternatives to Cronbach's alpha reliability in realistic conditions: congeneric and asymmetrical measurements. Front Psychol. https://doi.org/ 10.3389/fpsyg. 2016.00769

27. Revelle W, Zinbarg RE (2009) Coefficients alpha, beta, omega, and the glb: comments on Sijtsma. Psychometrika 74:145-154. https://doi.org/10.1007/s11336-008-9102-z

28. Hu L, Bentler PM (1999) Cutoff criteria for fit indexes in covariance structure analysis: conventional criteria versus new alternatives. Struct Equ Model A Multidiscip J 6:1-55. https://doi. org/10.1080/10705519909540118

29. McGraw KO, Wong SP (1996) Forming inferences about some intraclass correlation coefficients. Psychol Methods 1:30-46. https://doi.org/10.1037/1082-989X.1.1.30

30. Fairburn CG, Beglin S (1994) Assessment of eating disorders: interview or self-report questionnaire? Int J Eat Disord $16: 363-370$

31. Calugi S, Milanese C, Sartirana M et al (2017) The Eating Disorder Examination Questionnaire: reliability and validity of the Italian version. Eat Weight Disord Stud Anorex Bulim Obes 22:509-514. https://doi.org/10.1007/s40519-016-0276-6

32. Cohen J (1988) Statistical power analysis for the behavioral sciences. Lawrence Erlbaum Associates Inc., Hillsdale

33. Manzoni GM, Rossi A, Pietrabissa G et al (2021) Structural validity, measurement invariance, reliability and diagnostic accuracy of the Italian version of the Yale Food Addiction Scale 2.0 in patients with severe obesity and the general population. Eat Weight Disord Stud Anorex Bulim Obes 26:345-366. https://doi.org/10.1007/s40519-020-00858-y 
34. Citrome L (2019) Binge eating disorder revisited: what's new, what's different, what's next. CNS Spectr 24:4-13. https://doi. org/10.1017/S1092852919001032

35. de Zwaan M, Müller A, Allison KC et al (2014) Prevalence and correlates of night eating in the German general population. PLoS One 9:e97667. https://doi.org/10.1371/journal.pone.00976 67

36. Heriseanu AI, Hay P, Corbit L, Touyz S (2017) Grazing in adults with obesity and eating disorders: a systematic review of associated clinical features and meta-analysis of prevalence. Clin Psychol Rev 58:16-32. https://doi.org/10.1016/j.cpr.2017.09.004

37. Cena H, Barthels F, Cuzzolaro M et al (2019) Definition and diagnostic criteria for orthorexia nervosa: a narrative review of the literature. Eat Weight Disord Stud Anorex Bulim Obes 24:209-246. https://doi.org/10.1007/s40519-018-0606-y

38. Chwyl C, Berry MP, Manasse SM, Forman EM (2021) Rethinking emotional eating: retrospective and momentary indices of emotional eating represent distinct constructs. Appetite 167:105604. https://doi.org/10.1016/j.appet.2021.105604

39. Hoek HW, van Hoeken D (2003) Review of the prevalence and incidence of eating disorders. Int J Eat Disord 34:383-396. https:// doi.org/10.1002/eat.10222

40. Smink FRE, van Hoeken D, Hoek HW (2013) Epidemiology, course, and outcome of eating disorders. Curr Opin Psychiatry 26:543-548. https://doi.org/10.1097/YCO.0b013e328365a24f

41. Curtin R, Presser S, Singer E (2000) The effects of response rate changes on the index of consumer sentiment. Public Opin Q 64:413-428. https://doi.org/10.1086/318638

Publisher's Note Springer Nature remains neutral with regard to jurisdictional claims in published maps and institutional affiliations. 